\title{
How Online Grocery Stores Support Consumer Nutrition Information Needs
}

\author{
Kelly Olzenak, $\mathrm{MPH}, \mathrm{RD}^{1}$; Simone French, $\mathrm{PhD}^{1}$; Nancy Sherwood, $\mathrm{PhD}^{1}$; \\ Joseph P. Redden, $\mathrm{PhD}^{2}$; Lisa Harnack, DrPH, $\mathrm{RD}^{1}$
}

\begin{abstract}
Objective: To evaluate the availability of nutrition-related information and features on leading online grocery store Web sites.

Methods: Twelve US grocery Web sites were assessed to determine (1) if Nutrition Facts panel or ingredient statements were available for 26 food items; and (2) if options to filter or sort search results by nutritionrelated food attributes were available.

Results: Nutrition Facts panel and ingredient statement information were available for most foods for which this information is required on product packaging ( $85 \%$ of foods). Most stores offered the ability to filter food search results by a nutrition-related food attribute. The ability to sort search results by a nutrition attribute was not an option at any of the stores.

Conclusions and Implications: Online grocery stores include a variety of nutrition-related features. However, the Nutrition Facts panel and ingredient statement information are not universally available for foods for which this information is required on product packaging.

Key Words: Internet, food, consumer behavior, Internet shopping, nutrition labeling (J Nutr Educ Behav. 2020; 52:952-957.)
\end{abstract}

Accepted July 18, 2020.

\section{INTRODUCTION}

According to a 2017 Gallup poll, close to $10 \%$ of US adults reported shopping for groceries online, ${ }^{1}$ with steady growth in online grocery shopping projected according to grocery industry market research. ${ }^{2}$ However, according to grocery industry market reports online grocery shopping surged in early 2020 as a result of the

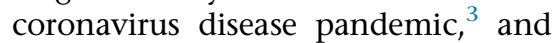
some industry experts speculate that even greater growth than previously predicted may occur because the habit of shopping for groceries online is apt to become ingrained for some. ${ }^{4}$
Another factor that may spur growth in online grocery shopping is acceptance of Supplemental Nutrition Assistance Program (SNAP) Electronic Benefits Transfer by online retailers. In April of 2019, the US Department of Agriculture Food and Nutrition Service announced the launch of the SNAP Online Purchasing Pilot program in several states to ensure online transactions may be carried out safely and securely before rolling out nationally. ${ }^{5}$ In response to the coronavirus disease, the US Department of Agriculture announced that the pilot had been rapidly expanded in 2020 to cover $90 \%$ of SNAP households. ${ }^{6}$

${ }^{1}$ Division of Epidemiology and Community Health, School of Public Health, University of Minnesota, Minneapolis, MN

${ }^{2}$ Carlson School of Management, University of Minnesota, Minneapolis, MN

Conflict of Interest Disclosure: The authors have not stated any conflicts of interest.

Address for correspondence: Kelly Olzenak, MPH, RD, Division of Epidemiology and Community Health, School of Public Health, University of Minnesota, 1300 2nd St, Minneapolis, MN 55454; E-mail:kolzenak@gmail.com

(C) 2020 The Authors. Published by Elsevier Inc. on behalf of Society for Nutrition Education and Behavior. This is an open access article under the CC BY-NC-ND license. (http:// creativecommons.org/licenses/by-nc-nd/4.0/)

https://doi.org/10.1016/j.jneb.2020.07.009

The shift toward online grocery shopping has potential nutrition implications because this shopping format may include or lack information and features that support shoppers' efforts to make healthful food purchase decisions. When shopping for groceries in a physical store, some nutrition information is available to support healthy food purchase decisions. For example, in the US, Nutrition Facts panel and ingredient statement information is available on most prepackaged foods because of regulatory mandates. ${ }^{7}$ In addition, the physical store layout of products may be designed to assist shoppers in locating foods with certain nutrition attributes. ${ }^{8}$ Similar information and design features may or may not be included in virtual supermarkets. In addition, online grocery stores could include features to support healthy food choices not available or viable in a physical store. For instance, the option to filter food search results by nutritional attributes (eg, limits foods displayed to those that are low sodium) could be included to assist shoppers in identifying food products that align with their nutrition goals. In addition, the option to sort food 
search results by a nutrition attribute (eg, list foods in rank order by milligrams of sodium per serving) could be included as a feature.

There is burgeoning research on various aspects of online grocery shopping. ${ }^{9}$ For example, studies have been carried out to gauge interest in online grocery shopping, ${ }^{10}$ to evaluate uptake and satisfaction with online grocery shopping, ${ }^{9,11}$ to understand how shoppers navigate online grocery shopping Web sites ${ }^{12}$ and what information is used while shopping for food online, ${ }^{12-14}$ and to evaluate design features that may influence food choices made while shopping for groceries online. ${ }^{15}$ However, to the authors' knowledge, the availability of nutrition-related information and features within online grocery stores has not previously been evaluated. Thus, the current research was undertaken to describe nutrition-related information and features available within leading online grocery shopping Web sites in the US.

\section{METHODS}

Twelve online grocery shopping Web sites from online grocers in the US were included in this cross-sectional, observational study. The 12 retailers were selected for inclusion based on the following criteria: (1) a leading food retailer or online food retailer in the US or Minnesota; and (2) have at least 1 online grocery-ordering Web site. Market reports were relied on to identify leading retailers. ${ }^{16,17}$ Local retailers selected included Coborns, Hy-Vee, and Cub Foods, and leading countrywide retailers included Walmart, Amazon Prime Now, Amazon Fresh, Whole Foods, Whole Foods via Amazon Prime Now, Kroger, Albertson, H-E-B Grocery Co, and Meijer.

Data collection was carried out by 1 of the authors (K.O.) between August and September 2018. As a quality control measure, another researcher trained on the coding protocol independently coded a subset of the foods $(n=7)$ for all of the stores, and coding was compared with evaluator reliability. For each online grocer, information was collected through interfacing with the store's Web site using a 12-in laptop computer. Information was systematically collected and recorded in a spreadsheet as follows. First, the following general store information was recorded: the store's home/landing page and URL, date and time of information collection and entry, postal code entered to reach home/landing page, availability of store pick up option, and the availability of home delivery.

Next, searches were carried out to locate 26 food items identified $a$ priori. The food items were selected to ensure that at least 2 foods were represented from each of 8 major food product categories (produce, meat, dairy, grains, canned goods, snack foods, sweets, and beverages). The food product categories were selected to correspond with some of the major departments found in many grocery stores. Expert judgment based on research team members' knowledge of the food marketplace was used to choose food items considered more popular/common within each category. A combination of store and non-store brands were included.

A standard protocol was used to search for each of the 26 food items to ensure consistency in data collection. First, the food item name was entered into the food search bar. Search results were then reviewed to locate the matching food item. If a matching food item was not found, the food category the food belongs to was selected and scrolled through to locate the food item. If the item was not available on the online store Web site, an attempt was made to locate a close substitution item.

On locating a match or close matching food product, the ability to filter (limit) search results by 7 specific health/nutrition-related attributes (gluten-free, fat content, sodium content, calorie content, trans fat content, cholesterol content, and American Heart Association certification $^{18}$ ) were evaluated. An other nutrition-related attribute entry field was included in the data collection spreadsheet for recording any other nutrition-related filter options available. The option to sort search results by a nutrient (eg, sort foods in rank order by grams of fiber per serving) was determined (yes/no), and the data collection spreadsheet included an entry field for recording all of the nutrients for which a sorting option was available.

Information collected and recorded for each food item located on a grocer's Web site included the availability of Nutrition Facts panel and ingredient statement information. If available, the legibility of the information was classified as good or poor. Factors that resulted in label and ingredient information being classified as having poor legibility included the occurrence of 1 or more of the following: (1) information presented upside down or sideways, (2) a blurry image, or (3) font size too small for the coder to read. The locations of the Nutrition Facts panel and ingredient statement information were coded as being viewed from the main product information page (1) with no scrolling required, (2) with scrolling required to view on the same page, (3) within 1 click, or (4) within 2 or more clicks from the product information page.

All of the analyses were conducted using Excel (version 15.28, Microsoft Corporation, Redmond, WA, 2016). Means, frequencies, and percentages were calculated. Two sample 2 tailed $\mathrm{t}$ tests were conducted to compare the availability of Nutrition Facts panel and ingredient statement information for foods that require this information on product packaging vs foods that do not require this information. Findings with a $P$ value $<0.05$ were considered statistically significant. Per the US Food and Drug Administration, most prepared foods such as breads, cereals, canned and frozen foods, snacks, desserts, and drinks require this labeling. Foods that do not require nutrition labeling include raw produce (fruits and vegetables) and fish. ${ }^{7}$ Because this study was not considered human subjects research as per US Department of Health and Human Services guidelines $^{19}$ Institutional Review Board review was not required.

\section{RESULTS}

The availability of Nutrition Facts panel and ingredient statement information on the online grocery store Web sites varied across the 26 foods 
examined (Table 1). Overall, Nutrition Facts panel information was available for $82 \%$ of the foods examined across the 12 stores. Foods that require a label on product packaging were more likely to have Nutrition Facts panel information available online compared with foods that do not require this labeling (85\% vs $46 \%, P<0.001)$. Overall, ingredient statement information was available for $82 \%$ of the foods examined across the 12 stores. Foods that require an ingredient statement on product packaging were more likely to have ingredient statement information available online compared with foods that do not require this information (85\% vs $54 \%, P<0.001$ ).

Findings regarding ease of access and legibility of Nutrition Facts panel information for each food item are displayed in Table 2. Most commonly, Nutrition Facts panel information was found 1 click away from the product information page. The percent of foods with Nutrition Facts panels with good legibility varied, ranging from $9 \%$ to $100 \%$. The print being too small to read or blurry were the leading reasons legibility was rated as poor. Ease of access and legibility findings were similar for the ingredient statement (data not shown).

With respect to the availability of nutrition-related food search filters,

Table 1. Availability of Nutrition Facts Panel and Ingredient Statement Information for Each Type of Food Among Web Sites That Sell the Food Item, \% ( $n$ )

\begin{tabular}{|c|c|c|}
\hline Foods & Nutrition Facts Panel & Ingredient Staten \\
\hline \multicolumn{3}{|l|}{ Produce } \\
\hline Banana $(n=12)$ & $33(4)$ & $50(6)$ \\
\hline Baby carrots $(n=12)$ & $58(7)$ & $58(7)$ \\
\hline \multicolumn{3}{|l|}{ Meat } \\
\hline Ground beef, 85\% lean $(n=12)$ & $42(5)$ & $25(3)$ \\
\hline Hormel Black Label bacon $(n=9)$ & $88(8)$ & $88(8)$ \\
\hline Oscar Mayer deli fresh turkey breast $(n=10)$ & $80(8)$ & $90(9)$ \\
\hline \multicolumn{3}{|l|}{ Dairy } \\
\hline Skim milk $(n=12)$ & $83(10)$ & $83(10)$ \\
\hline Kraft cheddar cheese, sharp brick and/or block $(n=8)$ & $88(7)$ & $88(7)$ \\
\hline Chobani yogurt, blueberry on the bottom, nonfat greek $(n=11)$ & $100(11)$ & $73(8)$ \\
\hline \multicolumn{3}{|l|}{ Grains } \\
\hline Sara Lee honey wheat bread $(n=10)$ & $100(10)$ & $100(10)$ \\
\hline Store brand $100 \%$ whole wheat sliced bread $(n=10)$ & $50(5)$ & $50(5)$ \\
\hline General Mills Honey Nut Cheerios $(n=12)$ & $75(9)$ & $75(9)$ \\
\hline Kellogg Frosted Mini-Wheats $(n=10)$ & $90(9)$ & $90(9)$ \\
\hline \multicolumn{3}{|l|}{ Canned goods } \\
\hline Progresso chicken noodle soup $(n=10)$ & $100(10)$ & $100(10)$ \\
\hline Libby's whole kernel sweet corn, canned $(n=5)$ & $80(4)$ & $100(5)$ \\
\hline Store brand canned sweet corn $(n=12)$ & $92(11)$ & $92(11)$ \\
\hline \multicolumn{3}{|l|}{ Snack foods } \\
\hline Pepperidge Farms Goldfish $(n=9)$ & $100(9)$ & $100(9)$ \\
\hline Rold Gold tiny twist pretzels $(n=7)$ & $100(7)$ & $100(7)$ \\
\hline DiGiorno rising crust pepperoni pizza $(n=9)$ & $100(9)$ & $100(9)$ \\
\hline Chewy chocolate chip granola bars $(n=10)$ & $100(10)$ & $100(10)$ \\
\hline \multicolumn{3}{|l|}{ Sweets } \\
\hline Twizzlers strawberry licorice $(n=10)$ & $100(10)$ & $100(10)$ \\
\hline Oreo Double Stuf cookies $(n=10)$ & $100(10)$ & $100(10)$ \\
\hline Hershey's milk chocolate bars $(n=10)$ & $100(10)$ & $100(10)$ \\
\hline Store bakery chocolate chip cookies $(n=12)$ & $42(5)$ & $50(6)$ \\
\hline Blue Bunny vanilla ice cream $(n=7)$ & $100(7)$ & $100(7)$ \\
\hline \multicolumn{3}{|l|}{ Beverages } \\
\hline POM Wonderful $100 \%$ juice pomegranate $(n=12)$ & $83(10)$ & $83(10)$ \\
\hline Coca-Cola soda $(n=10)$ & $90(9)$ & $100(10)$ \\
\hline \multicolumn{3}{|l|}{ Summary statistics } \\
\hline Overall (all items) $(n=261)$ & $82(214)$ & $82(215)$ \\
\hline Items exempt from Nutrition Facts labeling ${ }^{a}(n=24)$ & $46(11)^{\mathrm{b}}$ & $54(13)^{c}$ \\
\hline Items for which Nutrition Facts labeling is required $(n=237)$ & $85(203)^{b}$ & $85(202)^{c}$ \\
\hline
\end{tabular}

attems exempt from Nutrition Facts panel labeling included bananas and baby carrots. The remaining items require labeling; ${ }^{\mathrm{b}} P<0.001$ from a 2-sample 2-tailed $t$ test for difference in Nutrition Facts panel availability for foods required to be labeled vs exempt from labeling; ${ }^{c} P<0.001$ from a 2-sample 2-tailed $t$ test for difference in availability of ingredient statement for foods required to have statement vs exempt from having statement. 


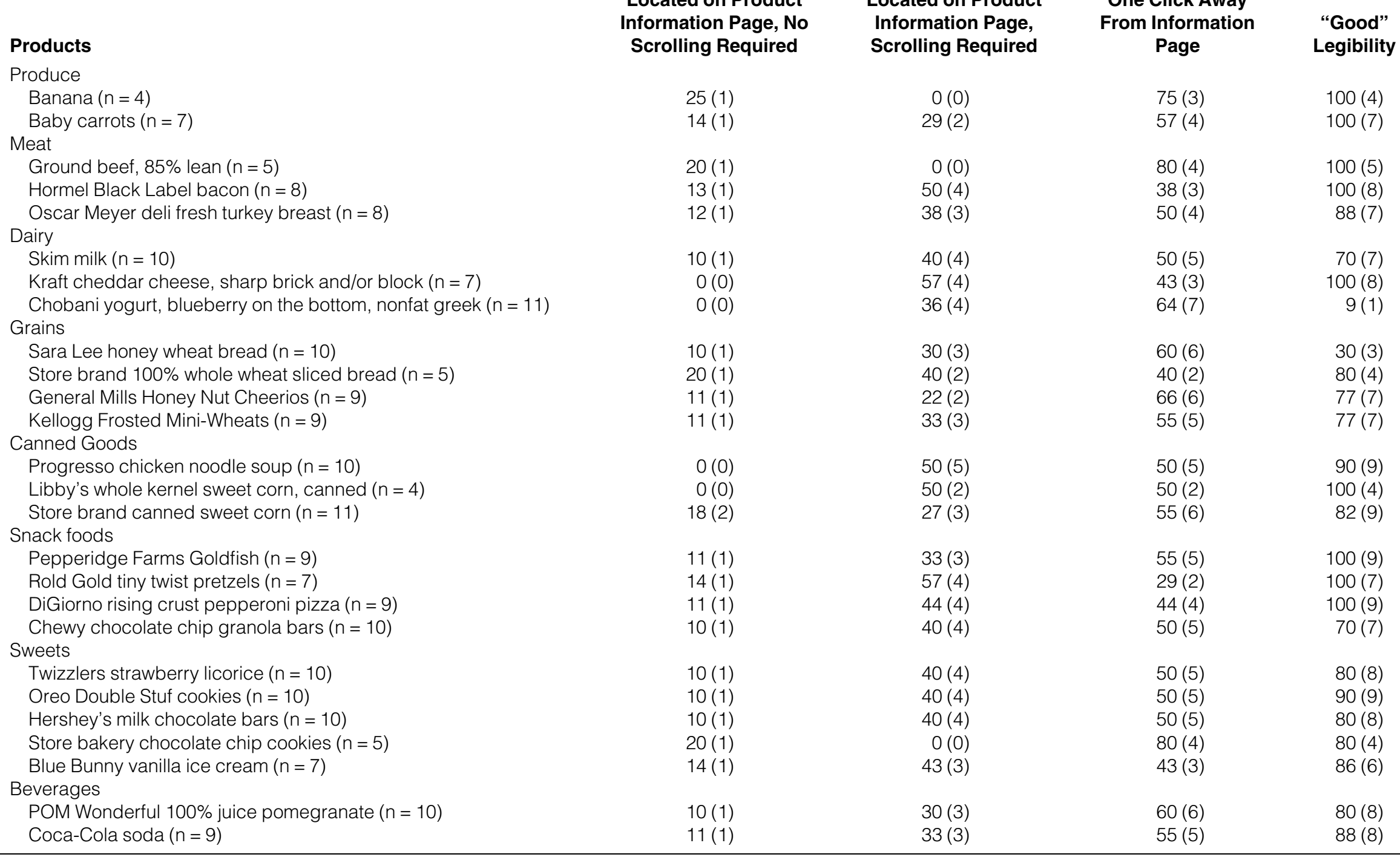

Note: Values are $\%(n)$.

\section{Located on Product formation Page, No}

$25(1)$

Banana $(n=4)$

Ground beef, $85 \%$ lean $(n=5)$

$13(1)$

$12(1)$

$10(1)$

$11(1)$

$0(0)$

$0(0)$

$11(1)$

$11(1)$

$10(1)$

$10(1)$

(1)

20 (1)

$10(1)$
Located on Product

Information Page,

0 (0)

$50(4)$

$40(4)$

$40(2)$

$33(3)$

$50(5)$

$50(2)$

$44(4)$

$0(4)$

$0(0)$
One Click Away

Page

$100(4)$

(5)

$80(8)$

$8(7)$

$9(1)$

(3)

$80(4)$

77 (7)

$90(9)$

0

(9)

$00(9)$

$00(9)$

$70(7)$

$80(8)$

80 (4)

6 (6)

88 (8) 
most of the stores offered the option to filter search results by at least 1 nutrition-related attribute (Table 3). Gluten-free was the most commonly available filter option ( $n=9$ stores). Six stores included the option to filter search results so that only products low in fat or fat-free are displayed. Five stores allowed search results to be limited to sugar-free/no sugar foods.

None of the online grocery store Web sites provided the option to sort search results by a nutrition attribute (eg, sort foods by mg sodium per serving).

\section{DISCUSSION}

Online grocery stores have the potential to support good nutrition by serving as a source of food for those living in food deserts ${ }^{20}$ and for those with a lack of transportation or physical disabilities. ${ }^{21}$ In addition, online grocery stores have the potential to contribute to good nutrition by providing information and including features that support shoppers' efforts to make healthful food purchase decisions. $^{22}$ The current research found that some nutrition-related information and features were available within the leading online grocery shopping Web sites examined in the study.

Findings indicated that Nutrition Facts panel and ingredient statement information were generally, but not universally, available for foods for

Table 3. Number and Percent of
Online Grocery Store
Web Sites With the
Option to Filter Food
Search Results by Vari-
ous Nutrition Attributes
$(\mathbf{n}=12)$
Filter
Gluten-free
Fat content
Sugar-free or no sugar
added
Sodium content
Calorie content

which this information is required on product packaging $(85 \%$ of the packaged foods had nutrition facts panel and ingredient statement information available). As a result, shoppers who rely on Nutrition Facts panel and ingredient statements for making food purchase decisions may sometimes need to look elsewhere for this information when shopping for some groceries online. Interestingly, the Nutrition Facts panel and ingredient statement information were sometimes available for produce items even though labeling is not required for these types of foods.

Most commonly, Nutrition Facts panel and ingredient statement information were found 1 click away from the product information page. A previous study examining online grocery shopping found that product information that required a click to access was rarely viewed, including Nutrition Facts panel $(4.2 \%)$ and ingredient statement (3.3\%) information pages. ${ }^{12}$ A survey of grocery shoppers carried out in February of 2018 by the International Food Information Council found that respondents were more likely to read the nutrition information on food packaging while shopping in stores compared with online. ${ }^{23}$ Online nutrition information that requires a click to access may be less used than nutrition information on the main product page.

Most stores in the study allowed food search results to be filtered by 1 or more nutrition-related food attributes. Previous research in which 40 adults were observed while they shopped for groceries online found that 95\% shopped through virtual departments similar to shopping patterns in a physical store (eg, shoppers may start with the produce section, then go to the dairy section, and then to the packaged foods section). ${ }^{12}$ Filters have the potential to expedite this shopping process if the shopper is trying to locate foods that meet their individual nutrition needs. This level of personalization is not typically feasible in a physical grocery store and highlights the potential for online grocery stores to support individual nutrition needs.

Study limitations include the nonrandom selection of online grocery stores, which may limit the ability to generalize findings beyond stores in the study. Furthermore, the fraction of the total market share these stores represent is unknown. Another notable limitation is the reliance on expert judgment in choosing specific food items to represent product categories. It would have been preferable to license sales data to objectively identify leading brands within a product category rather than rely on expert judgment, which may be biased. Additional limitations include: (1) completeness and accuracy of nutrition information provided were not evaluated, (2) foods selected by the research team may not represent the most commonly purchased foods and do not represent all food categories, and (3) data collection was carried out on a computer; thus, information and features available on mobile phones and tablets are unknown.

\section{IMPLICATIONS FOR RESEARCH AND PRACTICE}

Nutrition Facts panel and ingredient statement information were not universally available for food items for which labeling on product packaging is mandatory, and this information was not always easily accessed or legible. Consequently, when counseling, be aware that patients who shop for grocery online may not have access to nutrition facts panel and ingredient statement information for all food products while shopping. Other sources of nutrition information (eg, manufacturer's Web site) may need to be used in these instances.

Nutrition Facts panel information was sometimes available for produce items, even though labeling is not required for these types of foods. This nutrition information may be a novel way to inform and educate shoppers on the nutritional benefits of fruits and vegetables. In addition, this nutrition information may support patients who are aiming to choose or avoid foods rich in certain nutrients (eg, choose fruits and vegetables that are a good or excellent source of potassium, fiber, etc). However, the availability of Nutrition Facts panel information for produce could 
contribute to information overload, thereby potentially impeding nutrition-based decision-making.

In consideration of the limitations of this study and lack of prior research on the availability of nutrition facts panel and ingredient statement information in online grocery stores, rigorous research is needed to build a better understanding of the extent to which this information is lacking, potential reasons, and possible solutions. In addition, little is known about the use and effectiveness of other nutrition-related features found in this study included on some online grocery shopping Web sites; thus, further work is needed to evaluate and optimize the available features to support shoppers in making healthy food purchase decisions.

\section{REFERENCES}

1. Newport F, Brenan M. So far, American grocery shoppers buck online shopping trend. Gallup. August 8, 2017. https://news.gallup.com/poll/215597/ far-american-grocery-shoppers-buckonline-shopping-trend.aspx/Accessed July 19, 2019.

2. Weinswig D. Online grocery set to boom in 2018 (As Amazon acknowledges online grocery a tough market to crack). Forbes. March 1, 2018. https:// www.forbes.com/sites/deborahweinswig/2018/03/01/online-grocery-setto-boom-in-2018-as-amazon-acknowledges-online-grocery-a-toughmarket-to-crack/\#6c7bdbf0520b Accessed July 22, 2019.

3. Redman R. Online grocery shopping to grow $40 \%$ in 2020. SuperMarket News. May 11, 2020. https://www. supermarketnews.com/online-retail/ online-grocery-sales-grow-40-2020. Accessed June 29, 2020.

4. Soper T. COVID-19 crisis sparks 'inflection point' for online groceryand huge revenue for Amazon. Geek Wire. April 7, 2020. https://www. geekwire.com/2020/analyst-covid-19crisis-sparks-inflection-point-onlinegrocery-huge-revenue-amazon/ Accessed June 30, 2020.

5. US Department of Agriculture, Food and Nutrition Service. USDA launches SNAP online purchasing pilot. https:// www.usda.gov/media/press-releases/ 2019/04/18/usda-launches-snaponline-purchasing-pilot. Accessed June 29, 2020

6. US Department of Agriculture, Food and Nutrition Service. SNAP online purchasing to cover $90 \%$ of households. https://www.usda.gov/media/press-releases/2020/05/20/snap-online-purchasing-cover-90-households. Accessed June 29, 2020.

7. US Food and Drug Administration. Food labeling: revision of the nutrition and supplement facts labels. https:// www. federalregister.gov/d/201611867. Accessed June 29, 2020.

8. Martinez $\mathrm{O}$, Rodriguez $\mathrm{N}$, Mercurio A, Bragg M, Elbel B. Supermarket retailers' perspectives on healthy food retail strategies: in-depth interviews. BMC Public Health. 2018;18: 1019.

9. Jilcott Pitts SB, Ng SW, Blitstein JL, Gustafson A, Niculescu M. Online grocery shopping: promise and pitfalls for healthier food and beverage purchases. Public Health Nutr. 2018; 21:3360-3376.

10. Rogus S, Guthrie JF, Niculescu M, Mancino L. Online grocery shopping knowledge, attitudes, and behaviors among SNAP participants. J Nutr Educ Behav. 2020;52:539-545.

11. Martinez O, Tagliaferro B, Rodriguez N, Athens J, Abrams C, Elbel B. EBT payment for online grocery orders: a mixed-methods study to understand its uptake among SNAP recipients and the barriers to and motivators for its use. J Nutr Educ Behav. 2018;50. 396402.e1.

12. Benn Y, Webb TL, Chang BPI, Reidy J. What information do consumers consider, and how do they look for it, when shopping for groceries online? Appetite. 2015;89:265-273.

13. Harris P, Riley FD, Riley D, Hand C. Online and store patronage: a typology of grocery shoppers. Int J Retail Distrib Manag. 2017;45:419-445.

14. Clark L, Wright P. Off their trolley understanding online grocery shopping behaviour. Int Fed Infectol Proc. 2007;241:157.

15. Koutoukidis DA, Jebb SA, OrdonezMena JM, et al. Prominent positioning and food swaps are effective interventions to reduce the saturated fat content of the shopping basket in an experimental online supermarket: a randomized controlled trial. Int J Behav Nutr Phys Act. 2019;16:50.

16. Major M, Springer J. Exploring America's top 20 food retailers. Winsight Grocery. Business. July 17, 2018. https://www.winsightgrocerybusiness. $\mathrm{com} /$ retailers/exploring-americas-topfood-retailers \#page $=0$ Accessed June 29, 2020

17. Hanbury M. The most popular grocery store in every state. Business Insider. February 22, 2017. https://www.businessinsider.com/most-popular-grocery-store-in-each-state-2017-2. Accessed July 12, 2020.

18. American Heart Association, American Heart Association Heart-Check Certification Program. https://www.heart. org/en/healthy-living/company-collaboration/heart-check-certification. Accessed July 12, 2020.

19. US Food and Drug Administration, Department of Health and Human Services. Food Labeling: revision of the Nutrition and Supplement Facts Labels. Final rule. Fed Regist. 2016; 81:33741-33999

20. Department of Health and Human Services. Human subjects decision regulation chart. https://www.hhs.gov/ ohrp/regulations-and-policy/decisioncharts/index.html\#c1. Accessed June 29, 2020.

21. Brandt EJ, Silvestri DM, Mande JR, Holland ML, Ross JS. Availability of grocery delivery to food deserts in states participating in the online purchase pilot. JAMA Network Open. 2019;2: e1916444.

22. DeVault N. Home delivery services serve up improved accessibility to food and more. https://www.ameridisability. $\mathrm{com} /$ post/home-delivery-servicesserve-up-improved-accessibility-tofood-and-more. Accessed June 29, 2020 .

23. International Food Information Council. National voter poll evaluating online grocery shopping. Washington, DC: Gallup; 2018. https://foodinsight.org/wp-content/ uploads/2018/03/Online-ShoppingHabits.pdf. Accessed June 29, 2020.

\section{ORCID}

Kelly Olzenak: http://orcid.org/00000002-6987-4502 